\title{
COMPETÊNCIAS EMPREENDEDORAS NOS PROFISSIONAIS DE ARQUITETURA: ANÁLISE DAS HISTÓRIAS DE VIDAS
}

Rafael Piacentini ${ }^{1}$

Marcelo Roger Meneghatti ${ }^{1}$

Roberto Lima Ruas ${ }^{2}$

\footnotetext{
${ }^{1}$ Universidade Estadual do Oeste do Paraná

${ }^{2}$ Universidade Nove de Julho
} 


\section{COMPETENCIAS EMPREENDEDORAS NOS PROFISSIONAIS DE ARQUITETURA: ANÁLISE DAS HISTÓRIAS DE VIDAS}

Resumo: O objetivo é identificar as competências empreendedoras arquitetos que possuem escritórios próprios, compreendendo as capacidades necessárias para abrir e gerir seus negócios. Trata-se de uma pesquisa qualitativa, descritiva e exploratória, realizada por meio de entrevistas, realizadas entre março e maio de 2019. Os entrevistados foram selecionados por conveniência, a partir de critérios como: o tempo de formação e de atuação como empreendedor, além de necessariamente terem se graduado em instituição na cidade de Cascavel/PR. Sobre o corpus das entrevistas, foi realizada a análise do conteúdo utilizando o software Iramuteq, os resultados obtidos foram justificados com falas dos próprios entrevistados. Tais resultados apontam que um arquiteto que deseja empreender no contexto pesquisado precisa necessariamente dos conhecimentos de mercado, negócio, serviços e percepção pessoal. Este estudo contribui para entender a formação dos profissionais que empreendem em arquitetura e, a visualizar a necessidade da formação de competências empreendedoras durante a graduação em arquitetura.

Palavras-chave: Empreendedorismo. Negócios. Arquitetura. Percepção pessoal.

\section{$1 \quad$ Introdução}

Este estudo está determinado a compreender as competências empreendedoras dos profissionais de arquitetura, levando em consideração suas características e as configurações presentes nas atividades relacionadas ao empreendedorismo. Para tanto, foram analisadas as histórias de vida de um grupo de arquitetos que empreenderam. Foi possível assim concluir sobre algumas características que sondam estes profissionais na decisão de empreender.

É difícil definir empreendedorismo, pois os autores que se dedicam ao seu estudo acabam abordando-o da perspectiva de suas respectivas áreas (FILION, 1999; KURATKO et al., 2015). Sendo assim, enquanto economistas relacionam o empreendedorismo à inovação, comportamentalistas podem relacioná-lo à criatividade e intuição. Por isso, entende-se para este estudo que o empreendedor é um indivíduo capaz de perceber e aproveitar oportunidades para capitalizar, mesmo que assuma riscos (KIRZNER, 1973; DORNELAS, 2008; KIRKLEY, 2016). O conceito de empreendedor está atrelado ao da oportunidade, essa que pode ser descoberta ou criada, de modo que se torna indissociável ao empreendedor e a oportunidade, independente da natureza dela, se for criada ou encontrada (GAFURI, 2015).

Uma abordagem de estudo no contexto do empreendedorismo são as competências empreendedoras - objeto de estudo desta pesquisa - o termo competências empreendedoras pode ser entendido como as competências do indivíduo relacionadas à prática administrativa (MAMEDE; MOREIRA, 2005). Neste estudo, o conceito de competências empreendedoras utilizado foi sugerido por Man e Lau (2000), que destaca os indivíduos e possui seis classes, sendo elas: competência de oportunidade; de relacionamento; conceitual; administrativa; 
estratégica; e de comprometimento. A partir de tais classificações de competências foram realizadas as análises dos dados obtidos por meio das entrevistas.

Este estudo apresenta como problema de pesquisa a seguinte questão: Quais as competências empreendedoras presentes na história de vida dos profissionais de arquitetura da cidade de Cascavel/PR? Para responder a esta pergunta elenca-se o objetivo desta pesquisa: Identificar as competências empreendedoras de profissionais de arquitetura que possuem escritórios próprios, compreendendo as capacidades necessárias para abrir e gerir seus próprios negócios nesta atividade. Para alcançar este objetivo foi realizado um estudo exploratório, com apoio da metodologia qualitativa, e com análise de conteúdo das entrevistas. Estas análises se deram a partir do uso do software Iramuteq (sugiro nota de rodapé sobre o software), que teve a finalidade de encontrar os resultados pelas Análises de Classificação Hierárquica Descendente e da Análise de Similitude.

Para realização deste estudo foram coletadas entrevistas com arquitetos da cidade de Cascavel, Paraná, os quais deveriam seguir requisitos prédeterminados (menos de 15 anos de formação e de marca e/ou negócio próprio, além de terem se formado em uma Instituição de Ensino Superior - IES - na própria cidade). A amostra foi escolhida por conveniência e as entrevistas realizadas entre março e maio de 2019.

De modo geral, os resultados encontrados no contexto pesquisado demostram que para um arquiteto empreender são necessárias competências empreendedoras que englobem: Mercado, Serviço, Negócio e Percepção Pessoal. Essas dimensões quando comparadas com as competências empreendedoras se relacionam da seguinte forma: Mercado se refere à competência de oportunidades; Serviços se refere à competência estratégica; Negócio se refere às competências administrativas; Percepção Pessoal se refere às competências de comprometimento, relacionamento e conceitual, tais relações foram obtidas por meio deste estudo, de modo que são resultados dele.

As contribuições deste estudo estão na compreensão de quais as competências empreendedoras são adequadas para um arquiteto que deseja, ou necessita, abrir seu próprio escritório. Dessa forma, é possível preparar os acadêmicos de arquitetura para o processo de abrir e gerir um negócio próprio.

\section{$2 \quad$ Referencial Teórico}

A literatura é confusa quanto à definição de empreendedorismo e tal confusão ocorre, pois, os pesquisadores tendem a utilizar premissas de suas áreas específicas. Isso pode ser observado com vários pontos de vista como o dos economistas que associam o empreendedorismo aos aspectos de inovação, por outro lado os comportamentalistas se apoiam nos aspectos de criação e intuição (FILION, 1999).

Filion (1999) explica que Cantillon e Say foram pioneiros nos estudos sobre empreendedorismo, ainda no século XIX, assumindo o risco como característica empreendedora, uma vez que os indivíduos investiam suas próprias economias em seus negócios. Segundo Cantillion (2011), estes empreendedores compram a matéria prima, a processam e então a revendem, o que demonstra que, para este autor, o empreendedor está ligado à indústria e seus processos.

As definições não chegam a um consenso, pois os pesquisadores possuem a tendência de estudar o empreendedorismo segundo suas próprias disciplinas (FILION, 1999), portanto, 
para a economia o empreendedorismo se relaciona com a inovação devido a associação feita por Schumpeter, como lembra Cantillion. Já os comportamentalistas - psicólogos, psicanalistas, sociólogos e demais estudiosos do comportamento humano - atribuem como característica do empreendedor a necessidade de realização, o principal autor dessa ideia foi McClelland (1961) que também atribuiu ao empreendedor o papel de figura que exerce controle sobre uma produção que não seja de seu consumo exclusivo.

O empreendedor é definido como um indivíduo capaz de perceber oportunidades e criar negócios para capitalizar sobre eles, assumindo riscos calculados (KIRZNER, 1973; DORNELAS, 2008; KIRKLEY, 2016). Também é compreendido como um indivíduo criativo, com capacidade de estabelecer e atingir objetivos mantendo consciência do ambiente em que se insere e utilizando essa consciência para perceber as possibilidades de negócio (FILION, 1999).

Dentro desse mundo de empreendedorismos, uma abordagem que se destaca são as competências empreendedoras que, podem ser entendidas tanto como a competência do indivíduo, como podem ser relacionadas às práticas administrativas (BOYATZIS, 1982; MAMEDE; MOREIRA, 2005). Já para Man e Lau (2000), as competências são características que destacam os indivíduos e as classificam em seis tipos, que podem ser observadas na Tabela 01 .

Tabela 01: competências empreendedoras de Man e Lau

\begin{tabular}{l|l}
\hline Competência & Descrição \\
\hline Competência de oportunidade & $\begin{array}{l}\text { Se refere a habilidade de reconhecer uma oportunidade de } \\
\text { negócio. }\end{array}$ \\
\hline Competência de relacionamento & $\begin{array}{l}\text { Competência relacionada às relações e interações interpessoais } \\
\text { e dos indivíduos com o grupo }\end{array}$ \\
\hline Competência administrativa & $\begin{array}{l}\text { Se refere as diferentes habilidades conceituais do individuo que } \\
\text { se refletem em seu comportamento como empreendedor }\end{array}$ \\
\hline Competência estratégica & $\begin{array}{l}\text { É a competência que se refere a capacidade de gestão da } \\
\text { organização, sejam seus recursos financeiros, físicos, } \\
\text { tecnológico, humanos ou materiais }\end{array}$ \\
\hline Competência de comprometimento & $\begin{array}{l}\text { É a competência que se refere a capacidade de visualização dos } \\
\text { cenários e planejamento para atingir os objetivos a médio e } \\
\text { longo e prazo. }\end{array}$ \\
\hline Fongalo & $\begin{array}{l}\text { O comprometimento é a competência da dedicação, que por sua } \\
\text { vez proporcionam a manutenção do negócio. }\end{array}$ \\
\hline
\end{tabular}

Fonte: Adaptado de Man e Lau, 2000, p. 237-238.

Zarifian (2001) classifica as competências organizacionais em: a) técnicas, referentes a conhecimentos específicos; b) processuais, referentes aos processos e operações; c) organizacionais, referentes a organização e controle dos fluxos; d) as de serviço e sociais, que se referem a responsabilidade e comunicação no ambiente organizacional. Se faz necessário apresentar essas competências organizacionais para que elas não se confundam com as competências empreendedoras, que são o foco desta pesquisa.

As competências empreendedoras se definem como a união entre conhecimentos, habilidades e atitudes que permitem ao indivíduo apresentar sua visão, estratégia e ações para criação de valores à sociedade (ANTONELLO, 2006; KURATKO et al., 2015). Ainda como definição as competências, sejam individuais ou coletivas, são recursos da organização que devem ser aproveitados na melhoria do desempenho em competitividade, aperfeiçoamento ou 
criação de novos recursos que mantenham um negócio no mercado (MENEGHATTI; HSE; RUAS, 2017). A partir desta perspectiva, as competências empreendedoras de um indivíduo também podem ser entendidas como um recurso que apoia à decisão e ao ato de empreender.

As competências empreendedoras ainda podem ser entendidas como um conjunto de conhecimentos, habilidades, qualidades, características, visões, atitudes e direcionamentos que, como apontado por Snell e Lau (1994), contribuem efetivamente com o negócio, viabilizando ações e estratégias para o posicionamento deste. Nassif, Andreasse e Simões (2011), encontraram resultados em seus estudos que demonstram que as competências empreendedoras são vitais para o sucesso de um negócio, sua pesquisa demonstrou que os empreendedores possuem competências focadas em variáveis que influenciaram suas vidas - como motivações, apoio familiar, modo de conduzir seu negócio e até mesmo a possibilidade de construir uma carreira como empreendedor.

Alguns autores se dedicam a criar tipologias que possibilitem os pesquisadores identificarem os elementos que compõe as competências empreendedoras (COOLEY, 1990; MAN; LAU, 2000). Cooley (1990) apresenta uma lista com dez competências empreendedoras, sendo elas; procura de oportunidade e iniciativa, persistência, comprometimento, exigência de qualidade e eficiência, calculo de riscos, estabelecimento de metas, pesquisa e informação, planejamento e monitoramento sistemáticos, persuasão e netwroking, independência e autoconfiança. Já para Man e Lau (2000), que realizaram estudos empíricos entre 1993 e 1999, as competências empreendedoras podem ser dividas em seis áreas; competências de oportunidade, relacionamento, conceituais, administrativas, estratégicas e de comprometimento, como observado anteriormente.

De acordo com Zampier, Takahashi e Fernandes (2009) os modelos de Cooley (1990) e Man e Lau (2000) apresentam como competências, características que a rigor a literatura não aponta como competências. Entre essas características estão o comprometimento, a independência, a autoconfiança, e a persistência, pois, estas características estão mais próximas de traços de personalidade ou aspectos comportamentais.

Mesmo com a crítica de Zampier, Takahashi e Fernandes (2009), vários estudos adotam os modelos de Cooley (1990) e Man e Lau (2000) (MORALES, 2004; PAIVA JR.; LEÃO; MELLO, 2003; MAMEDE; MOREIRA, 2005, FONSECA et al., 2006; HONMA, 2007; DIAS; NARDELLI; VILLAS BOAS, 2008; HONMA; TEIXEIRA, 2011). Todas estas pesquisas abordam - com suas particularidades - temas referentes ao empreendedorismo, as particularidades dos empreendedores e as dificuldades que eles enfrentam para abrir e manter seus negócios. Porém, pesquisar sobre empreendedorismo sem considerar as tipologias de empreendedores é arriscado, pois elas são úteis uma vez que possibilitam analises e comparações entre os dados a fim de identificar padrões de comportamento ou fenômenos na vida dos empreendedores.

Em pesquisas sobre empreendedorismo frequentemente identificam-se diferentes tipos de empreendedores (KURATKO et al., 2015). Após analisar as tipologias de proposta por diversos autores que o antecederam, Filion (1999) então pode propor sua própria tipologia, criada com base nos critérios de quatro regras sistêmicas: Inter-relação, informação, hierarquia. $\mathrm{O}$ autor também considerou elementos chave sendo: visão, relações internas e externas à empresa, energia dedicada as práticas profissionais e liderança. Com base nesses critérios, foram propostos seis tipos de empreendedores, o lenhador, o sedutor, o jogador, o hibbysta, o 
convertido e o missionário (FILION, 1999). Ainda foi citado o empreendedor voluntário, aqueles que por algum motivo não foram capazes de se inserir ou reinserir no mercado de trabalho então seguiram pelo caminho de empreender. Já o involuntário seria aquele opta pela vida de empreendedor (FILION, 1999).

Podemos definir, dessa forma, que o empreendedor voluntário é um empreendedor por necessidade, uma vez que está comprometido com seu negócio e concentra sua energia nele. Já o empreendedor involuntário é um empreendedor por oportunidade e que, mesmo tendo escolhido esse caminho, precisa de motivações externas, como a identificação da oportunidade, pois sem isso continuaria em seu mundo comum.

Métodos

A metodologia utilizada para elaboração desta pesquisa é exploratória e qualitativa constituída de revisão teórica, desenvolvimento e aplicação dos instrumentos para coleta de dados e ainda o procedimento de análise dos dados. O estudo foi realizado na cidade de Cascavel, no estado do Paraná-Brasil, cidade localizada na região oeste deste estado, com pouco mais de 300 mil habitantes e, de acordo com o Conselho de Arquitetura e Urbanismo - CAU , conselho profissional que regulamenta a profissão dos sujeitos objetos de estudo, possui 338 profissionais registados e 187 empresas do seguimento. Desse modo, por se tratar de um estudo exploratório, é uma pesquisa que pretende construir bases para pesquisas similares de maior escala.

Ressalta-se que, devido a natureza qualitativa desta pesquisa, ela é predominantemente interpretativa, como definido por Creswell (2007). Os pesquisadores interpretaram os dados recolhidos por meio de entrevistas - que seguem um roteiro semiestruturado - realizadas com dez arquitetos, uma amostra escolhida por conveniência. Para escolha da amostra foram estabelecidos os seguintes requisitos: o entrevistado não poderia possuir mais de 15 anos de formado, deveria ser graduado necessariamente em Arquitetura e Urbanismo em alguma Instituição de Ensino Superior - IES - da cidade onde o estudo foi realizado, e seu negócio também não poderia ter mais de 15 anos de existência, ressalta-se que as entrevistas foram realizadas nos ambientes dos próprios entrevistados, na Tabela 02 é possível observar a síntese da amostra.

Optou-se por utilizar os critérios de seleção para escolha da amostra com objetivo de evitar conflitos de geração, pois se notam mudanças nos indivíduos de diferentes gerações (GRASSI; ANDRADE; VELOSO, 2016). As mudanças são presentes em traços de comportamento, posicionamento e até mesmo qualificações. As mesmas se alteram cada vez mais rápido devido ao fenômeno da globalização e das revoluções tecnológicas, informacionais e de comunicação.

Tabela 02: Controle dos sujeitos entrevistos

\begin{tabular}{llllcr}
\hline Sujeitos & Formação & Sexo & Enquadramento & $\begin{array}{c}\text { Tempo } \\
\text { empreendimento }\end{array}$ & $\begin{array}{c}\text { do } \\
\text { Ano de formação }\end{array}$ \\
\hline Sjcvel001 & Arquitetura & Feminino & Microempresa & 12 & 2006 \\
Sjcvel002 & Arquitetura & Feminino & Autônoma & 01 & 2016 \\
Sjcvel003 & Arquitetura & Feminino & Autônoma & 05 & 2011 \\
Sjcvel004 & Arquitetura & Feminino & Microempresa & 03 & 2013 \\
Sjcvel005 & Arquitetura & Feminino & Eireli & 02 & 2014 \\
Sjcvel006 & Arquitetura & Masculino & Autônomo & 06 & 2007 \\
Sjcvel007 & Arquitetura & Feminino & Eireli & 01 & 2013 \\
\hline
\end{tabular}




\begin{tabular}{llllll}
\hline Sjcvel008 & $\begin{array}{l}\text { Arquitetura } \\
\text { lengenharia }\end{array}$ & Feminino & Eireli & 05 & 2013 \\
Sjcvel009 & Arquitetura & Feminino & Autônoma & 07 & 2012 \\
Sjcvel010 & Arquitetura & Ambos & Sociedade Ltda & 05 & 2014 \\
\hline
\end{tabular}

Fonte: Elaborado pelos autores, 2019.

A opção de não utilizar os nomes dos entrevistados, mas sim um código de referência, foi adotada com a intenção de deixá-los mais a vontade para responder as perguntas. Da mesma forma, nomes de terceiros ou de organizações - incluindo as suas próprias - também foram censurados e não serão citados neste estudo.

As entrevistas foram realizadas entre março e maio de 2019, gravadas no empreendimento dos entrevistados e posteriormente transcritas para realização das análises. A partir dos textos coletados, por meio dos entrevistados descritos na Tabela 02, foi construído o corpus utilizado nesta pesquisa. Para isso foram transcritas e transformadas em um arquivo único com formato de txt,, o material foi analisado com o apoio do Software Iramuteq 0.7 Alpha 2 (Interface de R pour lês Analyses Multidimensionnelles de Textes et de Questionnaires), $\mathrm{O}$ intuito do uso do software Iramuteq foi de realizar uma análise de conteúdo textual para conhecer o corpus a ser pesquisado.

Foram realizadas duas análises com o sistema Iramuteq. A Primeira foi a Classificação Hierárquica Descendente, cujos resultados são apresentados por um gráfico de Dendrograma. Esta primeira análise dividiu o corpus em grupos de palavras, de acordo com suas semelhanças semânticas, gerando assim uma relação hierárquica das palavras no texto, e separando-as em classes que posteriormente foram também analisadas de maneira manual no texto. Ou seja, as classes criadas pelo software são formadas pelas relações entre as palavras no texto, o que proporciona um resultado estatístico para compreensão do corpus (Marchand \& Ratinaud, 2012; Reinert, 1990).

A segunda análise foi a de Similitude das palavras. Dela se origina um gráfico de rede de palavras, mostrando as relações que cada núcleo de palavras possui no texto. Sendo as palavras mais fortes representadas pelo tamanho da fonte na rede, e as relações pelos traçados criados entre as palavras (Reinert, 1990). Esta análise diferente da anterior, ajuda na compreenção do corpus verificando a quantidade de repetição das palavras e suas relações entre si.

Por fim, foram demostradas a partir de Tabelas os resultados da análise de conteúdo, que teve origem no resultado da Classificação Hierárquica Descendente e, posteriormente, em formato de texto, a Análise de Similitude. Dados, analises e resultados obtidos podem ser observados na seção seguinte.

\section{$4 \quad$ Resultados e discussões}

$\mathrm{Na}$ análise do corpus composto pelas dez entrevistas coletadas foram identificados 22.129 ocorrências de palavras, 624 seguimentos de textos - fragmentação gerada pelo Iramuteq. As classes identificadas pelo software podem ser observadas no Dendrograma, Figura 02 abaixo.

Figura 02: Dendrograma das palavras do corpus analisado 


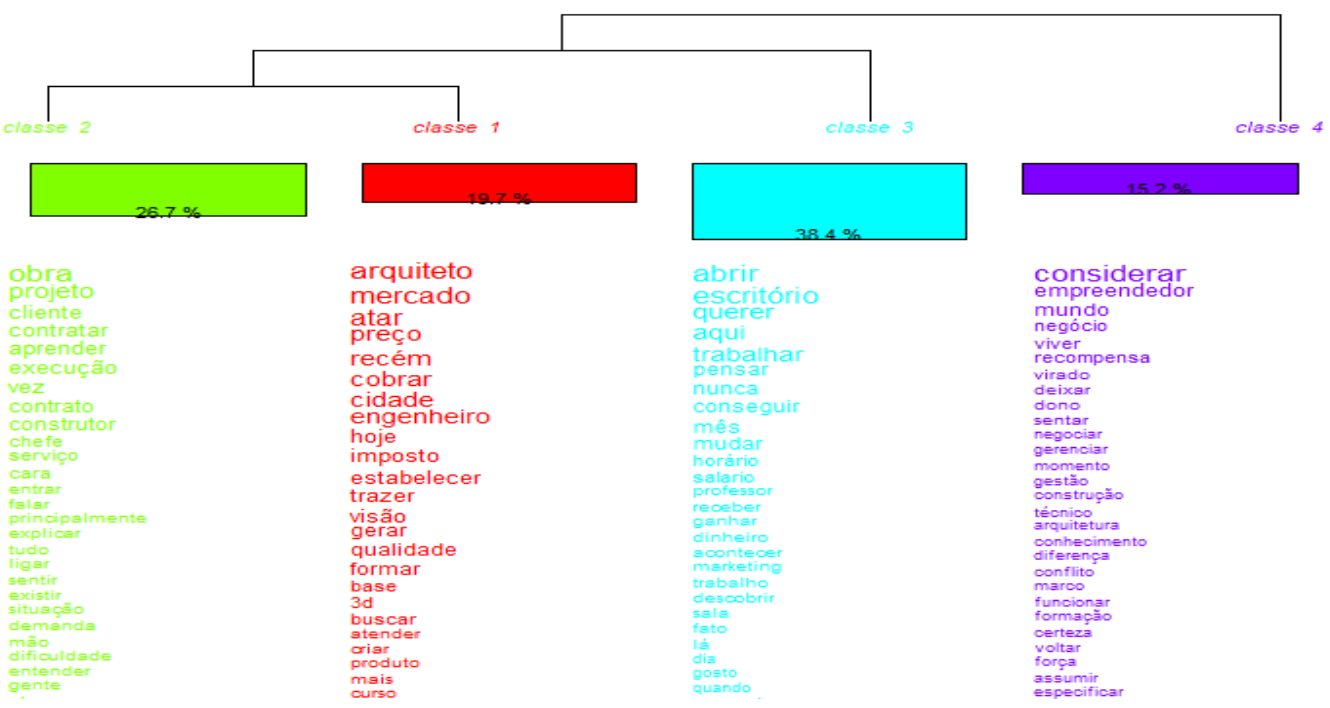

Fonte: Dados da pesquisa, 2019.

O dendrograma acima apresenta quatro clusters que formam 3 conjuntos. O primeiro composto pelas classes 1 e 2, que juntamente com a classe 3 forma o segundo conjunto e que somado a classe 4 compõe o terceiro. Ao analisar as ligações entre classes nota-se que as classes 1 e 2 tem maior relação entre si e também se referem aos serviços e mercado dos entrevistados, demostrando que estes estão intimamente relacionados, além de estarem direta ou indiretamente ligadas às outras duas classes. Essa relação fica ainda mais evidente ao se observar as dimensões das variáveis do texto, Figura 03 a seguir.

Figura 03: Dimensões das variáveis do texto

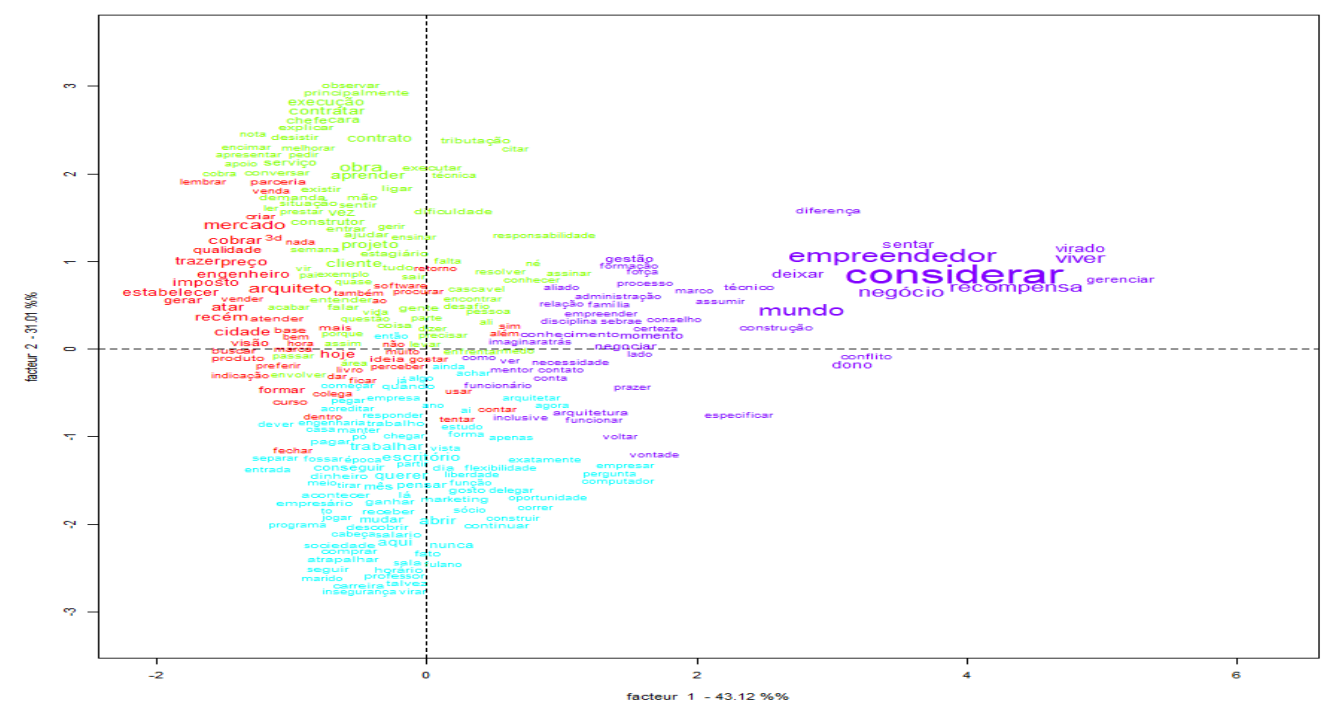

Fonte: Dados da pesquisa, 2019.

Observando a Figura 03, fica evidente como as classes 1 e 2 se misturam e se relacionam diretamente a classe 3 , ficando mais distantes da classe 4 , contudo ainda mantendo relação.

A partir da observação e análise dessas figuras, nomeou-se as classes da seguinte forma: classe 1) Mercado; classe 2) Serviços; classe 3) Negócio; classe 4) Percepção pessoal. Quanto 
à hierarquia representada pela porcentagem, percebe-se que a classe 3 é a que justifica uma maior parte do texto, e ao se observar as palavras que a compõe percebe-se que esse grupo se refere ao negócio - chamado pelos entrevistados principalmente de escritório. A segunda é a classe 2, que se refere aos serviços prestados pelos entrevistados, sua natureza, relação com clientes, fornecedores e empregados. A classe 1 está na terceira posição de hierarquia e se refere às questões de mercado e as relações do entrevistado e seu negócio com aspectos deste. Por fim, no patamar mais baixo da hierarquia está a classe 4, que faz referência à percepção dos entrevistados do seu eu enquanto empreendedores, algo que eles aparentemente têm dificuldade, percebendo-se mais como arquitetos. No quadro 01, pode-se observar falas dos entrevistados que corroboram com a definição destas classes e as justificam, as frases foram escolhidas com base no resultado de palavras apresentado no Dendrograma.

Quadro 01: Recortes das entrevistas que corroboram a analise do Dendrograma

\begin{tabular}{|c|c|c|}
\hline Classe & Transcrição & Sujeito \\
\hline \multirow[t]{7}{*}{ Mercado } & $\begin{array}{l}\text { "(...) eu tenho dificuldade, por exemplo, com a parte tributária e fiscal, a parte } \\
\text { contábil, é uma parte que eu gostaria de conhecer melhor porque eu realmente tenho } \\
\text { dificuldade (...) eu uso o mesmo intelecto de arquiteta para ter essa visão voltada para } \\
\text { o futuro, então em geral eu estou sempre um passo à frente, tentando perceber qual o } \\
\text { próximo movimento de mercado, quanto de tendência, até na forma de prestar um } \\
\text { serviço, em gerenciamento(...)" }\end{array}$ & SJCVEL001 \\
\hline & $\begin{array}{l}\text { "(...) A té hoje não consegui por preço no meu trabalho, então eu não estou ganhando } \\
\text { dinheiro, estou pagando para trabalhar basicamente." }\end{array}$ & SJCVEL002 \\
\hline & $\begin{array}{l}\text { "(...) Olha pelo mercado, eu não atendo o público AA, eu atendo o público médio e } \\
\text { pra isso eu faço uma pesquisa de mercado com colegas e jogo meu preço, hoje meu } \\
\text { arquitetônico esta } 40,00 \text { por } \mathrm{m}^{2} \text { apesar de eu entregar alguns diferenciais (...) então o } \\
\text { mercado que rege (...)" }\end{array}$ & SJCVEL003 \\
\hline & $\begin{array}{l}\text { "Acho que o maior desafio é a tributação. Pois o que eu poderia investir de outra } \\
\text { forma, quem sabe contratando outra pessoa para me auxiliar eu não posso fazer, pois } \\
\text { a tributação me bloqueia. Por exemplo, sempre que eu faço um projeto, só ali na nota } \\
\text { fiscal ficam } 17 \% \text { do valor do preço do projeto. Claro como o escritório ainda é novo, } \\
\text { é um valor que pesa nas contas mensais, além disso, todo dia é um desafio na } \\
\text { verdade." }\end{array}$ & SJCVEL004 \\
\hline & $\begin{array}{l}\text { "(...) hoje não consigo ver ninguém como inimigo ou concorrente, mesmo sabendo } \\
\text { que essa visão existe massivamente dentro do ramo, por parte dos profissionais } \\
\text { leigos, recém formados e isso não ocorre só entre arquitetos, mas engenheiros } \\
\text { competem com engenheiros e engenheiros com arquitetos, isso gera uma competição } \\
\text { desleal porque quando você entende que olha eu como arquiteta posso fazer uma } \\
\text { parceria contigo onde nos dois vamos ganhar por fazer um projeto mais rico, dividir } \\
\text { lucro, sempre tenho parceria com engenheiros (...)" }\end{array}$ & SJCVEL005 \\
\hline & $\begin{array}{l}\text { "Eu acho que o que eu tive bastante resultado assim, que as pessoas vinham falar } \\
\text { comigo e eu me sentia merecedora daquilo, porque ocorreu tudo certo. Eu vejo que } \\
\text { eu tenho projetos importantes (...) tem a precificação e a questão de você estar., olha } \\
\text { eu acredito que assim se eu tivesse funcionários delegar funções seria difícil até onde } \\
\text { vai a função de cada um? Outra coisa que eu posso citar é que assim quando eu } \\
\text { comecei meu contrato tinha uma folha hoje eu tenho } 8 \text { ou } 9 \text { e a cada obra eu aprendo } \\
\text { mais (...)" }\end{array}$ & SJCVEL009 \\
\hline & $\begin{array}{l}\text { "Como nos não recebemos reserva técnica ou outras comissões, então nós temos um } \\
\text { preço alto e quando colocamos isso para um cliente ele acha que somos caríssimos, } \\
\text { quando na verdade nós não somos, nós cobramos muito menos do que seria justo.(...) } \\
\text { Um segundo fator é o próprio mercado que faz as pessoas não procurarem um } \\
\text { arquiteto. Quando um engenheiro diz que pode fazer projeto isso arrebenta. (...) a } \\
\text { qualidade também pela metade, quando ele poderia se concentrar na sua }\end{array}$ & SJCVEL010 \\
\hline
\end{tabular}




\begin{tabular}{|c|c|c|}
\hline & $\begin{array}{l}\text { especialidade, cada um no seu quadro, o que geraria produtos melhores, maior } \\
\text { satisfação ao cliente. Nós, quando vendemos um projeto, nós vendemos a ideia do } \\
\text { especialista, nós como arquitetos somos especialistas em projetos arquitetônicos, nós } \\
\text { não fazemos projetos complementares (...)" }\end{array}$ & \\
\hline \multirow[t]{8}{*}{ Serviços } & $\begin{array}{l}\text { "(...) Hoje os clientes fazem fila de espera para que eu execute minhas obras fazendo } \\
\text { uma gestão transparente e ética, até porque é uma garantia de que o projeto vai ser } \\
\text { executado conforme foi concebido, (...)antes os clientes me ligavam em desespero } \\
\text { podiam contratar a melhor construtora que me ligavam falando "Isa seu projeto está } \\
\text { errado", eu respondi não, não está errado, vocês não estão sabendo executar, a mas } \\
\text { isso não vai dar certo, sim vai dar certo, então eu percebi que acabava prestando um } \\
\text { serviço de graça fazendo toda uma assessoria de obra para que saísse como eu } \\
\text { imaginei e meu cliente ficasse satisfeito. (...)" }\end{array}$ & SJCVEL001 \\
\hline & $\begin{array}{l}\text { "(...) Meu maior medo era não saber cobrar, noção saber lidar com cliente porque } \\
\text { era uma coisa que eu nunca, esse tato com clientes. Projetar é uma coisa, fazer, mas } \\
\text { falar com clientes, apresentar vender o projeto é outra coisa, então esse é o meu medo } \\
\text { e ainda tenho esse medo. (...)" }\end{array}$ & SJCVEL002 \\
\hline & $\begin{array}{l}\text { "(...) o cliente dá muita atenção a isso, mais importante que essa apresentação é o } \\
\text { suporte técnico, eu tenho que conseguir explicar o porquê de tudo. Quando estou } \\
\text { apresentado um projeto a um cliente é quase uma aula (...)" }\end{array}$ & SJCVEL003 \\
\hline & $\begin{array}{l}\text { "Eu acredito que foi captar clientes e consequentemente recursos. Porque fazer } \\
\text { alguém confiar no seu trabalho quando você sai de quase nada requer muita saliva. } \\
\text { Então eu diria que convencer alguém que eu poderia realizar um bom trabalho mesmo } \\
\text { sendo desconhecida foi um grande desafio." }\end{array}$ & SJCVEL004 \\
\hline & $\begin{array}{l}\text { "(...)Não que eu tenha muitos projetos, mas cada projeto tem muitas fases e em cada } \\
\text { uma muito a ser feito, detalhamento é demorado e complexo. Às vezes por conta de } \\
\text { ser um escritório novo, não ter muito dinheiro para investir acabo tento apenas } 1 \\
\text { estagiária o que me sobrecarrega de trabalho(...)" }\end{array}$ & SJCVEL005 \\
\hline & $\begin{array}{l}\text { “(...) Outra coisa é a prospecção de clientes, em alguns momentos uma determinada } \\
\text { área de atuação de sobrepõe a outra, então maior demanda por projetos acústicos que } \\
\text { arquitetônicos e também tem todo o timing em que você fica envolvido na obra, } \\
\text { porque a gente cobra pelo projeto.(...) }\end{array}$ & SJCVEL006 \\
\hline & $\begin{array}{l}\text { "(...) tudo depende de mim, tudo, tudo, desde a criação, o atendimento ao cliente e } \\
\text { hoje com whatsapp a gente perde a privacidade, o tempo com a família, tudo, o tempo } \\
\text { livre é todo do cliente eles querem ver as coisas nos fins de semana (...)" }\end{array}$ & SJCVEL007 \\
\hline & $\begin{array}{l}\text { "nós percebemos que o grande problema é separar os serviços, o que é projeto e o } \\
\text { que é acompanhamento de obra, isso gera um clima negativo, explicar para o cliente } \\
\text { que o serviço do projeto é um, e o serviço de acompanhar a execução desse projeto é } \\
\text { outro serviço que precisam ser contratados separadamente. Até hoje temos } \\
\text { dificuldade nisso (...)" }\end{array}$ & SJCVEL010 \\
\hline \multirow[t]{3}{*}{ Negócio } & $\begin{array}{l}\text { “(...) Hoje a captação de cliente é algo orgânico. Eu estou formada há } 12 \text { anos e há } 4 \\
\text { anos a capitação acontece naturalmente, eu tinha medo de ficar sem cliente mas hoje } \\
\text { eu não fico. (...) mas qual foi estratégia de marketing que adotei, eu precisa ser vista, } \\
\text { precisava que meu trabalho fosse visto para então ser comprado e isso deu certo nos } \\
\text { primeiros } 5 \text { anos. (...)” }\end{array}$ & SJCVEL001 \\
\hline & $\begin{array}{l}\text { "(...) eu acho que abrir um escritório foi parte disso a vontade de trabalhar com várias } \\
\text { coisas e não ficar presa em uma coisa só. (...) Questão de fazer contratos com clientes, } \\
\text { uma coisa que a gente não tem costume, fiz muitos projetos sem contrato e acabei } \\
\text { levando a pior. Questão de negociação e a captação de clientes porque na arquitetura } \\
\text { é muito indicação, a gente precisa, não sei não tem marketing na faculdade mas } \\
\text { deveria ter.” }\end{array}$ & SJCVEL002 \\
\hline & $\begin{array}{l}\text { “(...) No começo capitar clientes foi natural, eu sempre postava, desde a época da } \\
\text { faculdade eu tinha lá minhas paginas e sempre postava, veja só como é importante a } \\
\text { rede social (...) Quase não tenho conhecimento em gestão, mas com a construtora eu }\end{array}$ & SJCVEL003 \\
\hline
\end{tabular}




\begin{tabular}{|c|c|c|}
\hline & $\begin{array}{l}\text { posso perguntar para os meninos da engenharia, então, por exemplo, se um cliente } \\
\text { me pede nota eu recorro a eles e então posso explicar para o cliente, olha se eu te } \\
\text { emitir a nota será } 15 \% \text { a mais, referente aos impostos, nós trabalhamos com } \\
\text { transparência, dentro do que a lei e o fisco exigem. Estamos no simples nacional, que } \\
\text { não é nada simples." }\end{array}$ & \\
\hline & $\begin{array}{l}\text { "Eu acredito que foi captar clientes e consequentemente recursos. Porque fazer } \\
\text { alguém confiar no seu trabalho quando você sai de quase nada requer muita saliva. } \\
\text { Então eu diria que convencer alguém que eu poderia realizar um bom trabalho mesmo } \\
\text { sendo desconhecida foi um grande desafio. (...) O planejamento é essencial para } \\
\text { quem quer começar a empreender. Claro algumas empresas apenas acontecem você } \\
\text { pode abrir uma loja ali na esquina e ela simplesmente ser um sucesso, mas e daqui a } \\
\text { dez ou quinze anos? (...)". }\end{array}$ & SJCVEL004 \\
\hline & $\begin{array}{l}\text { "A grande dificuldade foi conseguir novos clientes, porque quando você abre você } \\
\text { não tem nome, não tem padrinho e também não tem grande aporte financeiro para } \\
\text { investir em marketing, então levei } 6 \text { meses para finalmente fechar o primeiro } \\
\text { contrato(...) Problemas da própria gestão, por falta de conhecimento, nesse momento } \\
\text { busquei ajuda do sebrae, cursos, acic, na acic encontrei outros profissionais na mesma } \\
\text { situação e acabamos nos ajudando. Dificuldades quanto a precificação do serviço, } \\
\text { captação de clientes, fechamento de contratos, legislação, tributação, contador. (...)" }\end{array}$ & SJCVEL005 \\
\hline & $\begin{array}{l}\text { "É, a questão da gestão de você colocar tudo no papel o que ganha e o que gasta, pra } \\
\text { mim como arquiteta esse é o maior desafio porque eu não entendo da parte } \\
\text { administrativa. Cobrar o cliente, essa parte pra mim é bastante difícil, então, o que } \\
\text { mais, ah acho que seria isso." }\end{array}$ & SJCVEL007 \\
\hline & $\begin{array}{l}\text { "Criar uma folha de pagamento, e saber fazer a parte administrativa. Saber fazer um } \\
\text { pró-labore, calcular impostos, saber o preço da sua hora, saber cobrar o cliente. Toda } \\
\text { essa parte ligada ao direito e a administração é muito complicada, porque a gente } \\
\text { não tem nada na faculdade, absolutamente nada, a gente não tem, não tem. Eu na } \\
\text { minha grade não tive, só orçamento de obra mas que não faz diferença na vida de } \\
\text { administrar um negócio. (...)" }\end{array}$ & SJCVEL008 \\
\hline & $\begin{array}{l}\text { “(...) Eu acho que a precificação é muito difícil, até hoje eu no decorrer da obra, } \\
\text { percebo que cobrei pouco, ou muito, esse é um desafio que eu enfrento até hoje. Mas } \\
\text { é difícil falar porque eu sou a empresa, não tenho funcionários por enquanto, então } \\
\text { tem a precificação (...) Outra coisa que eu posso citar é que assim quando eu comecei } \\
\text { meu contrato tinha uma folha hoje eu tenho } 8 \text { ou } 9 \text { e a cada obra eu aprendo mais } \\
\text { (...)” }\end{array}$ & SJCVEL009 \\
\hline & $\begin{array}{l}\text { “(...) não sabendo planejar a gestão de projeto, além da gestão empresarial, faltou } \\
\text { gestão de projetos, como eu faço, como eu organizado as etapas, eu preciso fazer as } \\
\text { coisas em que tempos? (...) Depois disso tudo estabelecemos alguns padrões de } \\
\text { comportamento dentro do escritório de como fazer as coisas, estabelecemos um } \\
\text { padrão de qualidade e procedimento, mas até hoje temos dificuldade em precificar, } \\
\text { fechar negócio e ajustar a gestão de negócio, quem dirá a gestão de negócio. (...): nós } \\
\text { sabemos que existe custo fixo e variável e não sei o que, a gente sabe que existe, nós } \\
\text { vimos a cartilha do Sebrae mas a gente não aplica nada, a gente dá aula, então entra } \\
\text { o dinheiro dessas aulas, entra o dinheiro dos projeto mas tudo vira uma bola de neve } \\
\text { o que sai, e está tudo uma bagunça, porque faltou na nossa formação uma disciplina } \\
\text { pra aprender a gerir um escritório.(...)" }\end{array}$ & SJCVEL010 \\
\hline \multirow[t]{3}{*}{$\begin{array}{l}\text { Percepção } \\
\text { Pessoal }\end{array}$} & $\begin{array}{l}\text { "(...) há conflitos, há dias em que eu preciso ser mais a empresária do que a arquiteta } \\
\text { e eu estou na vibe super criativa querendo desenhar ou pintar um quadro aí eu vou } \\
\text { pintar, porque eu respeito muito a minha natureza que é de múltiplas facetas." }\end{array}$ & SJCVEL001 \\
\hline & $\begin{array}{l}\text { "Eu cresci bastante, todo mundo aprende, aprende com os erros experiência é por } \\
\text { isso que é importante você tentar, tentar aprender, usar a internet, é muito bom." }\end{array}$ & SJCVEL002 \\
\hline & $\begin{array}{l}\text { "(...) se fora contar hoje eu tenho mais anos de experiência como autônoma do que } \\
\text { como funcionária ou estagiária,(...)" }\end{array}$ & SJCVEL003 \\
\hline
\end{tabular}




\begin{tabular}{|c|c|}
\hline $\begin{array}{l}\text { "(...) Eu tinha muita dificuldade de expressão antes de empreender, isso até me fez } \\
\text { pensar duas vezes se eu daria certo como empresária, mas existe um interruptor } \\
\text { interno que a gente liga e as coisas começa a acontecer e eu consigo agora me } \\
\text { expressar como quero dentro do meu trabalho." }\end{array}$ & SJCVEL004 \\
\hline $\begin{array}{l}\text { "(...) você ser empresário e correr riscos, dar a oportunidade de trabalho e } \\
\text { conhecimento para outras pessoas te torna uma pessoa diferente é passar a olhar do } \\
\text { outro lado da prancheta, outro ponto de vista. (...). Quando você é empresa além de } \\
\text { fiscalizar tarefas, você precisa se preocupar com questão de gerenciamento, } \\
\text { prospecção de clientes, legislação e contratos, parcerias, novas possibilidade, acho } \\
\text { que isso é o que muda, o leque de percepção e cuidados aumenta (...)" }\end{array}$ & SJCVEL005 \\
\hline $\begin{array}{l}\text { "(...), tem diálogo entre o eu arquiteto e o eu empresário. Assim hoje eu penso muito } \\
\text { diferente de quando recém formado, o mercado ele, não que ele é duro, mas ele gerou } \\
\text { um choque de realidade. A arquitetura é uma formação muito idealista ela tem muito, } \\
\text { principalmente a fase do modernismo que envolve muito questões politicas que } \\
\text { assim, é bom mas é ruim, porque acaba dando essa paulada no cara e tem gente que } \\
\text { entende se adapta e tem gente que acaba migrando saindo da área." }\end{array}$ & SJCVEL006 \\
\hline $\begin{array}{l}\text { "Olha essas duas partes (arquiteta e empreendedora) estão tentando conversar pra } \\
\text { virar uma coisa só, mas eu não vejo como empresária completa porque pra mim um } \\
\text { empresário é quando ele faz uma empresa trabalhar sozinha, por isso eu acho que } \\
\text { ainda não sou empresária, sou mais arquiteta." }\end{array}$ & SJCVEL007 \\
\hline "Acho que não consigo me separar em arquiteta, engenheira e empresária. (...)” & SJCVEL008 \\
\hline $\begin{array}{l}\text { "Eu acho que como arquiteta, já que você acaba sendo a sua marca, eu vejo como } \\
\text { uma pessoa só né, arquiteta e marca. Eu me vejo uma pessoa diferente a cada dia, } \\
\text { como eu falei, a cada contrato aumenta uma cláusula então com certeza esse contato } \\
\text { com clientes e sempre me adaptando me faz ser diferente a cada dia, com certeza." }\end{array}$ & SJCVEL009 \\
\hline $\begin{array}{l}\text { "Eu acho que arquitetura é gestão pura, gestão de conflitos, de tempos, fluxogramas, } \\
\text { soluções de problemas. Eu desejo estar amanha um arquiteto meneger ligado a gestão } \\
\text { do negocio.(...) Eu também me vejo, acho que sou organizada, mas é a questão de } \\
\text { você não saber aplicar isso. (...)" }\end{array}$ & SJCVEL010 \\
\hline
\end{tabular}

Fonte: Dados da pesquisa, 2019.

É possível perceber que as falas dos entrevistados além de corroborarem com o resultado das análises pelo Iramuteq, também podem ser classificadas dentro das competências empreendedoras propostas por Man e Lau (2000), conforme pode ser visto na Tabela 03.

De modo geral os resultados demostram que para um arquiteto empreender, no contexto desta pesquisa, são necessárias competências empreendedoras que englobem Mercado, Serviço, Negócio e Percepção Pessoal. Essas dimensões, quando comparadas com as competências empreendedoras, se relacionam da seguinte forma: Mercado se refere à competência de oportunidades; Serviços se refere à competência estratégica; Negócio se refere às competências administrativas; Percepção Pessoal se refere às competências de comprometimento, relacionamento e conceitual.

Tabela 03: Competências empreendedoras x classes resultantes da análise

\begin{tabular}{ll}
\hline Competência & Classe \\
\hline Competência de oportunidade & Mercado \\
Competência de relacionamento & Percepção Pessoal \\
Competência conceitual & Percepção Pessoal \\
Competência administrativa & Negócio \\
Competência estratégica & Serviço \\
Competência de comprometimento & Percepção pessoal \\
\hline
\end{tabular}

Fonte: Resultados da pesquisa, 2019. 
Percebe-se que devido a imagem de arquiteto, empreendedor e da própria marca se misturarem a do indivíduo. A percepção pessoal se compara a maioria das competências empreendedoras, contudo ainda é nítido que as seis competências apresentados por Man e Lau (2000) são todas necessárias aos sujeitos graduados em arquitetura que desejam empreender.

Esta analogia entre as competências mencionadas por Man e Lau (2000) e as classes encontradas neste estudo, representam uma contribuição significativa para pensar a formação de um empreendedor arquiteto. Principalmente por confrontar tais competências com a prática encontrada na realidade do dia a dia de quem empreende. Assim, o uso das competências e a própria busca pela formação individual para que elas sejam mobilizadas, ganham sentido neste campo de atuação do proficional arquiteto.

Outra análise realizada com uso do Iramuteq foi a análise de similitude, Figura 04, uma análise a qual se ancora na teoria dos grafos, de modo que possibilita a identificação das ocorrências entre as palavras, bem como seu resultado nas indicações de conexão entre as mesmas, o que permite a identificação da estrutura de representação (MARCHAND; RATINAUD, 2012).

Figura 04: Árvore de similitude

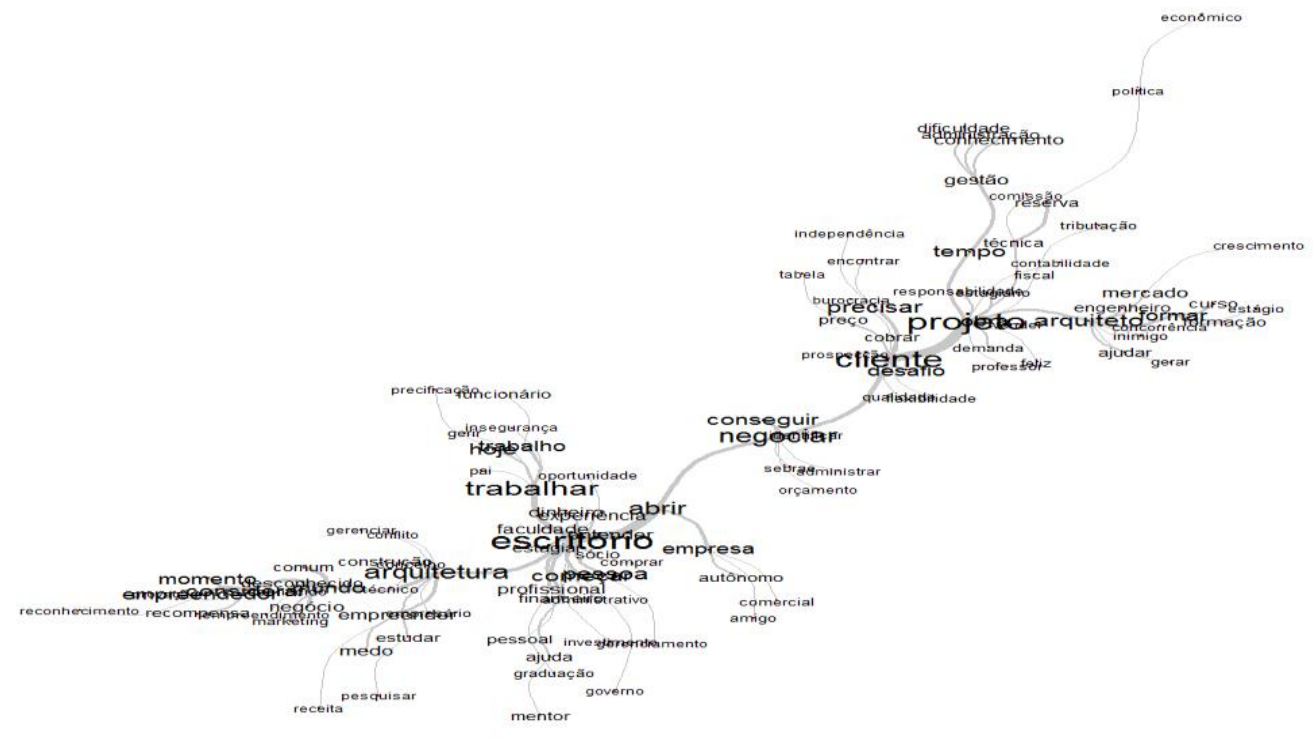

Fonte: Dados da pesquisa, 2019.

Nota-se na Figura 04 que a ramificação semântica das palavras dá-se a partir de um eixo principal, que possui 5 nós de ramificação, sendo eles; arquitetura, escritório, negociar, cliente e projeto. É interessante perceber que o nó na palavra negociar é uma espécie de centro estruturante do qual se ramifica toda a árvore, além de ligar escritório e cliente, ou seja, a capacidade de negociar é a ponte entre o negócio (escritório) e o cliente. Do mesmo modo, arquitetura se liga diretamente a escritório por ser o serviço prestado, enquanto projeto se liga a cliente por ser o produto que ele consome. A distribuição das demais palavras nos ramos se refere aos desafios que os entrevistados enfrentam na manutenção e gestão de seus negócios.

Se comparar o resultado da imagem da análise por similitude, Figura 04 acima, com o Quadro 01, que apresenta os recortes das falas dos entrevistados, mais uma vez eles se 
complementam e corroboram os resultados obtidos de modo que as análises e seus resultados, dentro do contexto desta pesquisa se apresentam como verdadeiros.

Para finalizar, na próxima e última seção, se fará as considerações finais, apresentando ainda diretrizes para futuras pesquisas, uma vez que os resultados obtidos apresentam dados que permitem a expansão de estudos nesse campo.

\section{Considerações finais}

Iniciamos este estudo com a afirmação de Filion (1999) sobre a dificuldade de definir empreendedorismo devido as diferentes perspectivas pelas quais os autores abordam esta área de estudo. Depois construímos uma narrativa sobre as competências empreendedoras, elementos fundamentais aos indivíduos que desejam empreender, agora podemos finalizar esta pesquisa, uma vez que já possuímos resultados e os discutimos.

A limitante geográfica desta pesquisa não a invalida, apenas reforça a necessidade de expandir os estudos, aumentar as escalas de abrangência e, assim, comparar mais sujeitos, a fim de conhecer as competências necessárias para um determinado grupo profissional. Neste caso, os arquitetos, incentivando a serem empreendedores e manterem vivos seus negócios.

Por meio da análise das histórias coletadas pelas entrevistas observou-se que existem quatro classes de percepção quanto aos arquitetos empreendedoras. O mercado, classe referente as oportunidades que existem para um arquiteto abrir seu negócio, e que essa classe se relaciona com a competência oportunidade, uma vez que esta se faz necessária para o aproveitamento das oportunidades que surgem. O serviço, classe relacionada aos serviços prestados pelos arquitetos - normalmente projeto e execução de obras, sendo o primeiro a principal atividade destes profissionais - e que essa classe está ligada à competência de estratégia, uma vez que é necessário o conhecimento de quais os seus serviços e como eles são ofertados para traçar estratégias que permitam a esses profissionais aproveitar as oportunidades de mercado.

A terceira classe, o negócio em si, se refere à competência administrativa, um grande desafio para os sujeitos entrevistados, pois esses não tiveram contato com disciplinas de empreendedorismo ou gestão durante duas graduações, o que gerou uma lacuna e os forçou a serem criativos para superar estes desafios, mesmo que a maioria ainda tenha grandes dificuldades de ordem gerencial em seus negócios. A última classe se refere a percepção pessoal e se relaciona com três competências empreendedoras relacionamento pessoal, conceitual e comprometimento, esta classe demonstra que uma vez que o arquiteto se mistura ao empreendedor e a própria marca, se torna difícil desassociar estas personas, de modo que as competências também se misturam apesar de continuarem lá e, talvez, por essa mistura é que exista um grande comprometimento desses indivíduos com seus negócios.

Esses são os principais resultados obtidos com a pesquisa e as análises geradas pelo Iramuteq. É necessário, contudo, reforçar a necessidade de mais pesquisas nessa área, a fim de compreender melhor a relação desses profissionais com seus negócios. $\mathrm{O}$ empreendedor nasce por necessidade ou por oportunidade, mas sobrevive apenas o negócio gerenciado por profissionais que conseguem desenvolver suas competências.

Certamente houve limitações neste estudo, a limitação geográfica, devido a pesquisa se concentrar apenas em uma cidade. Contudo estas limitações podem ser superadas em trabalhos futuros, tomando este estudo como base, é possível ampliar a escala geográfica da pesquisa e realizar a coleta de dados por meio de questionário. A mudança de método na coleta de dados 
não facilitará apenas a ampliação, mas, também a própria análise dos resultados obtidos.

Outra limitação foi de natureza do conhecimento dos entrevistados devido as suas formações, os sujeitos entrevistados, como os próprios alegaram, não possuem conhecimentos sobre gestão, administração ou empreendedorismo. Esta limitação também pode ser superada pela aplicação de questionário como método de coleta de dados, pois este limita as opções de resposta, impedido que a amostra, ou população, divague em suas respostas.

Ressalta-se, mais uma vez, que este estudo contribui como material base para estas futuras pesquisas, uma vez que a análise de competências empreendedoras em profissionais da arquitetura é um tema de pesquisa que não foi explorado anteriormente. Certamente os estudos futuros não precisam se manter restritos a este público, pois pesquisas sobre competências empreendedoras podem - e devem - ser realizadas como todos os tipos de empreendedores, pois tais estudos contribuirão para o desenvolvimento das competências necessárias aos indivíduos que pretender empreender, independente de qual seja seu segmento de mercado.

\section{Referências}

BOYATZIS, R. E. The Competent Manager: A Model for Effective Performance. (J. W. \& Sons, Ed.). New York. 1982.

CANTILLON, R. Essai sur la nature du commerce en général. Paris, Institut Coppet, 2011. COOLEY, L. Entrepreneurship Training and the strengthening of Entrepreneurial Performace. Final Report. Contract No. DAN-5314-C-00-3074-00. Washington: USAID, 1990.

DIAS, T. R. F. V.; NARDELLI, P. M.; VILAS BOAS, A. A. Competências empreendedoras: um estudo sobre os empreendedores ganhadores do prêmio TOP Empresarial. Encontro De Estudos Sobre Empreendedorismo E Gestão De Pequenas Empresas, 5, 2008. São Paulo. Anais... São Paulo, SP, EGEPE, 2008.

DORNELAS, J. C. A. Empreendedorismo: Transformando ideias em negócios. $3^{\text {a }}$ ed. Rio de Janerio. Elsevier, 2008.

FILION, L.J. empreendedorismo: empreendedores e proprietários-gerentes de pequenos negócios. Revista de Administração, v.34, n.2, p.05-28. São Paulo, abril/junho, 1999.

FONSECA, F. R. B.; MELlO, S. C. B; PAIVA JR., F. G.; FERNANDEZ, N. C. M. Competências empreendedoras como atributos geradores de valor: um estudo de caso no setor de base tecnológica. Encontro Nacional de Estudos da Engenharia de Produção, 26, 2006. Fortaleza. Anais... Fortaleza, CE: ENEGEPE, 2006.

GAFURI, E. L. Construções teóricas sobre a oportunidade: criação ou descoberta? Revista Competitividade e Sustentabilidade - ComSus, Paraná, V. 2, N. 1, P. 48-62, Jan /Jun. 2015.

GIL, A. C. Como elaborar projetos de pesquisa. São Paulo: Atlas, 2002. 
GRASSI, J. A.; ANDRADE, M. S. de; VELOSO, E. F. R. Gestão de gerações em sistemas bancários. In: Revista Competitividade e Sustentabilidade - ComSus, Paraná, v. 3, n. 1, p. 11-27, Jan /Jun. 2016.

HONMA, E. T. Competências empreendedoras: estudo de casos múltiplos no setor hoteleiro em Curitiba. (Dissertação de Mestrado) - Universidade Federal do Paraná, 2007.

HONMA, E. T.; TEIXEIRA, R. M. Competências empreendedoras em hotéis de pequeno porte: estudo de múltiplos casos em Curitiba, Paraná. Revista Turismo Visão e Ação - Eletrônica, Vol. 13 - no 1 - p. 52-80 / jan-abr 2011

KIRKLEY, W. W. Entrepreneurial behaviour: the role of values. International Journal of Entrepreneurial Behavior \& Research, v. 22, n.3, 1-32. 2016.

KIRZNER, I. M. Competition and entrepreneurship. Chicago and London: by The University of Chicago. 1973.

KURATKO, D. F.; MORRIS, M. H.; SCHINDEHUTTE, M. Understanding the dynamics of entrepreneurship through framework approaches. Small Business Economics, v.45, n.1, 1-13. 2015.

MAMEDE, M. I. de B.; MOREIRA, M. Z. Perfil de competências empreendedoras dos investidores portugueses e brasileiros: um estudo comparativo na rede hoteleira do Ceará. In ENANPAD, 2005. Anais. Brasilia, DF.

MAN, T. W. Y.; LAU, T. Entrepreneurial competencies of SME owner/managers in the Hong Kong services sector: a qualitative analyses. Journal of Enterprising Culture, v.8, n. 3, p.235254, Sept. 2000.

MARCHAND, P., RATINAUD, P. L'analyse de similitude appliqueé aux corpus textuels: les primaries socialistes pour l'election présidentielle française (septembre-octobre 2011). In: Actes des lleme Journé es internationalesd'Analyse statistique des DonnéesTextuelles. JADT: Liége, 2012, p. 687-699

McClelland, D. C. The Achieving Society. Princiton, D. Van Nostrand, 1961. Livro online disponível em: https://babel.hathitrust.org/cgi/pt?id=mdp.39015003646802; view=1up;seq=7 acesso em: $15 / 03 / 2019$

MENEGHATTI, M. R. HSE, P. L. RUAS, R. L. Rotinas organizacionais como propulsoras na geração de conhecimento. Revista Competitividade e Sustentabilidade - ComSus, Paraná, v. 4, n. 2, p. 3-14, Jul/Dez. 2017.

MORALES, S. A. Relação entre competências e tipos psicológicos junguianos. 2004. 199 f. Tese (Doutorado) - Programa de Pós-Graduação em Engenharia de Produção, UFSC, Florianópolis, 2004. 
NASSIF, V. M. J.; ANDREASSE, T. SIMÕES, F. Competências empreendedoras: há diferenças entre empreendedores e intraempreendedores? Revista de Administração e Inovação, v.8, n. 3, p. 33-54, 2011.

PAIVA JÚNIOR, F. G.; LEÃO, A. L. M. de S.; MELlO, S. C. B. Competências empreendedoras em comportamentos de dirigentes de êxito socialmente reconhecido. In: Encontro Da Associação Nacional Dos Programas De Pós Graduação Em Administração, 27, 2003. Atibaia. Anais... Atibaia, SP: ANPAD, 2003.

REINERT, M. Alceste une méthodologie d'analyse des données textuelles et une application: Aurelia De Gerard De Nerval. Bulletin of Sociological Methodology/Bulletin de Méthodologie Sociologique, 26(1), 24-54. 1990.

SNELL, R.; LAU, A. Exploring local competences salient for expanding small business. Journal of Management Development, v.13, n.4, 1994.

ZAMPIER, M. A.; TAKAHASHI, A. R. W. FERNANDES B. H. R. Sedimentando as bases de um conceito: as competências empreendedoras. In: Coloquio sobre empreendedorismo e estratégia de empresas de pequeno porte, 2, 2009, Curitiba, Anais. Curitiba: PUC-PR, 2009. 